\title{
A FORMAÇÃO DO ESTADO BURGUÊS NO BRASIL
}

\section{Maria Cristina de Carvalho ${ }^{1}$}

\section{INTRODUÇÃO}

Os debates sobre a renovação política da Metrópole acirrados com a Revolução do Porto e, estrategicamente, o retorno da Família Real para Portugal como também o projeto constitucionalista português, que visava por fim ao Antigo Regime, veio culminar em 1822 na emancipação política do Brasil. Isto porque a elite portuguesa acreditava que o reflorescimento da economia de Portugal dependia do controle político e econômico da Metrópole em relação a sua mais bem sucedida Colônia - Brasil.

Este projeto metropolitano esbarrava no Tratado de 1810 se de fato teve legitimidade de sua investidura. Neste sentido, o caráter antibritânico do projeto português reforçava a hostilidade entre americanos e europeus. De 1820 com o debate relacionado ao retorno da Família Real até 9 de janeiro de 1822 - o dia do "Fico", ocorrerá intensos debates e questionamentos sobre os rumos que seguiria o Reino. Permaneceriam unidos, retornaria o Pacto Colonial, ou, enfim, o Brasil se tornaria independente.

As tensões que se inicia em 1821, no eixo Rio - Lisboa se transfere a partir de 1822, para o espaço brasileiro, com questionamentos contra e pró a permanência de D. Pedro no Brasil e sobre a manutenção do status de nação unidas.

Por sua vez, os conflitos internos, localizados nas províncias, acirraram ainda mais o clima que dirigiria a Colônia à independência. As capitanias do Nordeste e do Norte desde 1808 permaneceram ligadas administrativa e economicamente à Metrópole, elas não aceitaram que o poder central fosse transferido para o Rio de Janeiro (SILVA, 2006) e lutas ocorreram com objetivo de separação das províncias do norte das do sul do Brasil. 0 regionalismo marcava os interesses e projetos entre as elites do Centro Sul.

\footnotetext{
1 Mestranda em Ciências Sociais na Universidade do Recôncavo da Bahia. Email: chrilcarvalho@hotmail.com
} 
A vinda da Corte para o Brasil reforçou os vínculos de dominação sobre as províncias mais distantes e os projetos de integração nacional. Um ressentimento econômico e um ciúme nacional das capitanias mais distantes, em relação ao Centro-Sul brasileiro, sede da Monarquia e beneficiário das principais medidas desenvolvimentistas do governo joanino, fez aumentar os conflitos e o sentimento de regionalismo.

Os conflitos internos atrelados aos fatos externos culminariam na separação definitiva do Brasil de Portugal em 1822, formando, assim o estado brasileiro burguês. Estado este que continua sendo uma Monarquia governada pelo herdeiro do trono português.

\section{A FORMAÇÃO DO ESTADO BRASILEIRO BURGUÊS}

Não podemos falar sobre a formação do estado brasileiro sem compreender qual era o sistema político instalado no Brasil anterior a sua independência. A organização econômica e a estrutura social muito contribuíram para que houvesse uma ruptura política no Reino.

Antes em 1750, mudanças significativas já começaram em Portugal e no Brasil que viriam esbarrar na independência em 1822. Em Portugal, verificamos o início do período pombalino. Já no Brasil está década marcou o auge e o declínio da produção aurífera. Assim, o Brasil transforma-se em peça mestra dos domínios lusos, superando a própria Metrópole em peso econômico e demográfico (LINHARES, 1990). Por outro lado, observa-se o distanciamento das provinciais coloniais. Estado do Brasil e o Estado do Grão-Pará e Maranhão formavam um conjunto mal comunicado, com nódoas de povoamento isoladas e distantes.

O surgimento da economia e da sociedade do ouro no centro sul correspondeu a importantes resultados de integração nordeste/sul. Isso se verifica com o abastecimento das minas nos fluxos de boiadas e de escravos do Nordeste para Minas Gerais e no aparecimento de uma organização urbana nas zonas de mineração com a presença constante de autoridade metropolitana.

A imigração de portugueses e a importação de escravos africanos provocaram mudanças no peso demográfico, social, político e cultural do Centro Sul em 1763. Rio de Janeiro tornou-se um porto importador e escoador do ouro, 
mantendo Maranhão e o Grão-Pará relativamente isolado. Recife e Salvador eram também focos ativos da navegação costeira.

A falta de igualdade de distribuição de materiais e o aumento dos impostos em todas as províncias geraram insatisfação dos provincianos que não aceitavam pagar as mesmas taxas das províncias mais beneficiadas do centro-sul.

No Brasil, os níveis de prosperidade variavam muito de uma região para outra. Podemos vislumbrar um panorama animador. Na região das minas, o ouro e o diamante atravessavam um apogeu, já o Rio de Janeiro conhecia o crescimento comercial e agrícola importante. O Pará era mais rico que o Maranhão. A prosperidade da Bahia superava a de Pernambuco. Este quadro mantinha a ilusão de Portugal que no Novo Mundo a fonte de exploração era inesgotável.

Os colonos, por sua vez, desfrutavam de domínio político, o qual a Coroa durante o governo de Pombal procurou limitar. 0 marquês de Pombal era caracterizado como um mercantilista ilustrado, pois tentou articular o mercantilismo e a Ilustração como base de reforma do absolutismo. Observa-se neste período que a influência da tradição do reformismo ilustrado intensificara-se em Portugal. 0 poder do Estado estava fundamentado por uma teoria política, jurídica de base individualista e contratualista.

\begin{abstract}
No plano político, (o iluminismo) seu impacto levaria a uma reinterpretação da natureza dos governos, que repercutiu profundamente nas estruturas do Estado, a partir das novas concepções, gestadas desde o século XVII, acerca das origens da sociedade civil e política, do pacto ou contato entre governados e governantes, da natureza da soberania do regime ou sistema político mais racional, das liberdades e direitos inerentes a cidadania (SILVA, 2006, p. 31).
\end{abstract}

Essas ideias políticas influenciaram os estadistas luso-brasileiros, porém não havia ainda neste momento nenhuma intenção de ruptura entre os Reinos. Os problemas dos governos imperiais expressavam o legado do reformismo lusobrasileiro que protagonizaram a construção do Estado e da Nação do Brasil. Esse reformismo inicia-se com as reformas ilustradas pombalinas. As ideias ilustradas contaminavam velho estamento da sociedade aristocrática e os atores sociais emergentes, figuras da modernização: os homens letrados. 
Imbuídos de ricas experiências diplomáticas e científicas muito deles seguiram a tarefa de repensar os destinos do império português articuladamente aos da própria Monarquia Nacional, combinando assim o saber e poder.

Os teóricos e estadistas compreendiam que a restauração de Portugal e sua inserção na modernidade seriam possíveis pela busca do aproveitamento ultramar, em uma perspectiva de Império, sendo que o Brasil representava sua superioridade por conta de sua rica natureza. Silva (2006) propõe que

O momento que acenou com uma primeira ideia de Brasil, apreendido como unidade, como parte destacada do conjunto imperial, a partir de sua rica natureza, denunciando sua superioridade ante a pequena Metrópole, o que, simultaneamente, acentuava o teor e a abrangência das reformas necessárias à conformação de uma dinâmica desenvolvimentista, necessariamente vinculatória dos destinos do Reino e da Monarquia à preservação da unidade imperial (SILVA, 2006, p. 414).

A transferência da corte para o Brasil não foi apenas uma estratégia para fugir da invasão francesa, mas uma estratégia para manter o Brasil ligado a Portugal. A crise econômica, social e política que se encontrava Portugal e as rebeliões centralizadas no Brasil faziam a Metrópole temer em perder seu domínio sobre a sua mais destacada colônia, o Brasil.

Portugal sofria os efeitos de uma grave crise econômico-financeira quando a Família Real se transferiu para o Brasil. De acordo com Rompatto (2001), a vinda da família real para o Brasil fez com que a Colônia e a Metrópole formassem um único país, um Portugal transatlântico, ligados pelo cordão umbilical e dependentes dos interesses ingleses.

0 tratado de comércio e navegação, assinado em 1810, entre Portugal e Inglaterra estabelecia entre outros a garantia do trono à família de Bragança em troca de abrir os portos da colônia ao comércio britânico com baixas taxas alfandegárias em relação a outras nações. Este tratado apresenta o interesse de Portugal em manter seu domínio político sobre o Brasil, tal que a taxa paga por Portugal era superior à inglesa, 16\% e 15\% respectivamente (ROMPATTO, 2001).

Por outro lado, a transferência da corte para o Brasil com boa parte do aparato administrativo e a crise política atravessada por Portugal contribuiu para 
manter no Rio de Janeiro uma parte dos interesses lusitanos (NOVAIS, 1997). De acordo com a ideia de Novais (1997) e Matos (2005), é possível sugerir que a instalação da Corte no Rio de Janeiro colaborou decisivamente para alimentar o projeto de um "novo império" a partir do Brasil. Ao mesmo tempo em que essa contradição de ordem política seria responsável pela negação do Império português.

Os estadistas passaram a realizar suas posturas e projetos políticos no espaço luso-brasileiro redimensionando a postura política de Estado em função da própria dinâmica da sociedade. De acordo com Silva (2006), estadistas e intelectuais ilustrados assumiram a empresa de reformar o Velho Reino e formar uma nova articulação Colônia-Metrópole, sem comprometer as bases do sistema da colônia.

Porém, a base do sistema colonial foi derrubada com a Abertura dos Portos às nações amigas de Portugal. Este fato não agradou a burguesia mercantil portuguesa, pois detinha o privilégio do monopólio comercial entre a Metrópole e a Colônia. Sem a exclusividade do monopólio colonial, a burguesia não tinha como resistir à irrefutável concorrência britânica. Isso afetou ainda mais o relacionamento administrativo no Reino.

A vinda da família real para o Brasil em 1808 forneceu o desenvolvimento de uma política luso - brasileira de formação de uma nação. Como parte do Reino Unido, o Brasil seria o grande beneficiado com o liberalismo do novo governo revolucionário. Parte dos comerciantes, militares e funcionários portugueses juntaram-se aos liberais brasileiros (intelectuais e elementos das camadas médias), exigindo de D. João VI o cumprimento das decisões das Cortes.

Essa transferência não tomou o desfeche esperado pelos estadistas que defendiam a ligação entre o mundo da ciência e da política:

Contraditoriamente, um desfecho que assinalou a própria fragilização da coesão imperial mediante interesses e perspectivas diferenciados, a partir de então forjados pelos estadistas sediados em cada uma das porções imperiais (SILVA, 2006, p. 414).

As tensões por conta das múltiplas determinações dos interesses dos estadistas luso-brasileiros aglutinaram-se a partir de 1815, quando há uma 
discussão em relação ao lugar hegemônico do poder no mundo luso-brasileiro com o debate entre governadores do Reino e a elite política cortesã do Rio de Janeiro. Isso vai levar ao movimento vintista em agosto de 1820 em Portugal, mais conhecida como Revolução do Porto.

A Revolução do Porto foi uma associação de liberais intelectuais, militares e burocratas, sob a liderança de Manuel Fernandes Tomás. Foi a expressão dos interesses da burguesia metropolitana, ansiosa por destruir o ainda existente resquício da ordem feudal em Portugal, recuperar o domínio sobre o Brasil e dissolver o risco de tornar-se uma colônia inglesa. Representou, também, a superação da crise econômica, como a divergência entre a burguesia e os deputados em Cortes. Eles pregavam a expulsão dos ingleses e o retomo de D. João VI a Portugal, devidamente limitado por uma constituição. Enquanto não se evidenciava o seu caráter recolonizador o movimento vintista, teve amplo apoio de frações sociais brasileiras.

Essa Revolução manifestou-se contraditória ao seu conteúdo liberal por tornar visível seu caráter recolonizador. Ao restabelecimento do governo português, a burguesia esperava reconquistar a exclusividade do comércio com a colônia. Chegou a tramitar no Parlamento português um projeto recolonizador (ROMPATTO, 2001). Tal decreto serviu para inflamar a participação dos parlamentares brasileiros naquela Assembléia. Mesmo com posições diferenciadas, a maior preocupação dos brasileiros era manter o Reino Unido e o livre comércio. Eles defendiam a manutenção da união do reino em igualdade jurídica, política, econômica e social.

Segundo Souza (1998), as Cortes pretendiam estabelecer um contrato entre os homens liberais do império luso-brasileiro. Com base no pensamento ilustrado, considerava a monarquia parlamentarista como representação política do direito natural do povo, ou seja, dos proprietários. Essa política parlamentarista era composta por representantes dos reinos (ROMPATTO, 2001).

0 contrato entre os estadistas luso-brasileiros era um jogo político bem articulado entre os liberais portugueses, pois, ao mesmo tempo em que eles tentaram criar um regime constitucionalista, articulavam com o firme propósito de 
fazer o Brasil regressar ao sistema colonial, fechando os portos ao comércio com outras nações.

De acordo com Rompatto (2001), os liberais portugueses também temiam uma revolução liberal no Brasil que culminasse com a separação entre os, até então, Reinos. Mas esse não era o fim a que se visavam os deputados brasileiros enviados para Portugal. Antes, defendiam a manutenção da aderência Portugal/Brasil. Representantes da província paulista, José Bonifácio, Antônio Carlos de Almeida e Silva mais outros quatro deputados organizaram um documento com a proposta de unidade do Reino e igualdade de representação.

Os outros deputados representantes das demais províncias também demonstraram o desígnio de manter a união. Segundo Rompatto (2001), foram consideradas legítimas as reivindicações de ambos os lados, tanto a manutenção da unidade do império como a flexibilidade de comércio. Ainda assim, faltava encontrar uma solução sobre que rumo levaria o Brasil e Portugal.

O discurso Iluminista não ficou restrito ao continente europeu, ele atravessou o Atlântico. Os estadistas brasileiros comprometidos com a esfera do poder instrumentalizaram-se para defender sua visão política "adquirindo uma força reivindicatória no intuito de instaurar uma constituição própria ao Brasil e assegurar seus direitos" (SOUZA, 1998: 112). A Constituição que daria autonomia ao Brasil só iniciou o processo de formulação em 1823.

Muitos foram os limites impostos à assembléia. A ela foi estabelecido que se mantivesse toda a estrutura de poder deixada pelo Estado Joanino, organismos, mistérios e a própria legislação colonial e os tratados de comércio e navegação de Portugal com a Inglaterra. (ROMPATTO, 2001, p. 188)

A defesa do estabelecimento de uma Constituição que mantivesse a unidade do Império tencionava a unidade nacional e os interesses da elite latifundiária e escravista.

Durante as discussões da Constituinte ficou manifesta a intenção da maioria dos deputados de limitar o sentido do liberalismo e de distingui-lo das reivindicações democratizantes. Todos se diziam liberais, mas ao mesmo tempo se confessavam antidemocratas e antirevolucionários. As idéias revolucionárias provocavam desagrado entre os constituintes. A conciliação da liberdade com a 
ordem seria o preceito básico desses liberais, que se inspiravam em Benjamim Constant e Jean Baptiste Say. Em outras palavras: conciliar a liberdade com a ordem existente, isto é, manter a estrutura escravista de produção, cercear as pretensões democratizantes.(COSTA, 1979, p. 116)

A Constituição era uma estratégia para afastar os populares das tomadas de decisão, ou seja, uma tática para exterminar qualquer ameaça de revoluta como havia ocorrido no Haiti. Assim, representava o temor em levantes de escravos e revoltas das classes sociais menos favorecidas como foi o caso da Conjuração Baiana em 1798 e da Insurreição Pernambucana em 1817.

As elites defendiam com unhas e dentes a manutenção da ordem social. 0 projeto de identidade nacional articulado pela elite política do Brasil era uma estratégia de acalmar os ânimos enfurecidos das provinciais e, especialmente, propugnar a afirmação de uma ordem já organizada a favor dos interesses da aristocracia proprietária de terras e escravos. Rompatto (2001) cita o bispo Azeredo Coutinho como um conservador preocupado que as ideias ilustradas da Europa viessem solapar a ordem social.

[...] o belicoso bispo referia-se com inusitada virulência verbal aos desumanos e cruéis agentes ou sectários dos bárbaros Brissot e Robespierre, destes monstros com figura humana que pretendiam trazer para o Brasil os princípios filosóficos que davam sustentação à Revolução Francesa. Para ele, tratava-se de principio destruidor da ordem social, e cujo ensaio foi o transtorno geral da Pátria, (ROMPATTO, 2001: 188)

Podemos compreender que o fantasma de sublevação das massas e escravos emergia no horizonte de preocupação da elite brasileira nas vésperas da independência.

Os conflitos internos nas capitanias são entendidos a partir da fragilidade e instabilidade política. Os movimentos de 1817 e 1821, Pernambuco e Bahia, respectivamente, sinalizavam para a ligação de participação de índios e escravos fugitivos e libertos. Sendo que o movimento de 1817 foi totalmente sufocado pelos governos locais, Conde de Arcos e Luis do Rego, identificados como despostimos portugueses no movimento de 1821. 
$\mathrm{Na}$ Bahia, vamos encontrar o movimento com objetivos mais avançado, o movimento de Independência, localizado no Recôncavo, cidade de Cachoeira, especialmente.

A partir desse movimento, embora fincados no projeto da União entre os Reinos, as elites brasileiras viram-se na urgência de reelaborarem não apenas o pacto político entre as partes, como sua própria "definição nacional", já que o deslocamento da fonte de "legitimação do poder" para as Cortes lisboetas representava o rompimento do vinculo institucional anterior, colocando o Brasil em posição subordinada (SILVA, 2006, p. 415).

Os movimentos constitucionalistas foram sucessos no Pará e na Bahia, também, acompanhados pela adesão do Piauí, Maranhão e Pernambuco. Distante de agenciarem a separação entre Brasil e Portugal, estes movimentos buscavam prover os interesses locais, uma vez que estavam insatisfeitos com a sede do Reino no Rio de Janeiro. Mesmo buscando os interesses locais, impulsionaram a contexto de independência do Brasil. Já no Sul, o movimento constitucionalista, tinha objetivos vinculados à política e ao comércio da Metrópole centrado no Rio de Janeiro.

Com as revoltas internas, a aristocracia percebeu que devia evitar o retorno à antiga condição de Colônia e, ao mesmo tempo, impedir que a ruptura com Portugal ocorresse pelo processo revolucionário. Os estadistas luso-brasileiros a partir daí fecundaram no antigo projeto imperial a questão de representação política.

O propósito era romper com a Metrópole sem abalar a estrutura de privilégios, fundada na organização econômica e social dos senhores de terras e escravos. Tendo em vista essa estratégia de ação política, a independência foi efetuada por um grupo de pessoas que preconizava a manutenção da ordem social e de conciliar os conflitos existentes dentro da própria classe dominante.

Neste mesmo cenário, destacam-se ainda, divergências internas entre os representantes da elite politica: conservadores e liberais radicais. Os liberais radicais defendiam uma maior autonomia das províncias, a eleição direta e a limitação dos poderes de D. Pedro. Os conservadores resistiram a uma 
Constituinte, mas pressionados aderiram sob a defesa de uma rigorosa centralização política e a limitação do direito de voto. Representados por José Bonifácio, os conservadores mantiveram o controle da Constituinte.

A Constituinte era favorável à união entre Portugal e Brasil. Embora favorável à união, as cortes portuguesas exigem o retorno de D. Pedro. Por sua vez, a exigência do retorno do imperador a Portugal acelerou o processo de independência política, tornando o Brasil independente de Portugal em 1822.

Rompidas definitivamente as relações entre Brasil e Portugal, a classe dominate brasileira tratou de criar meios eficazes para manter a unidade nacional.

Tratavam-se de forjar uma unidade a partir das diversidades legadas por aquela herança e acentuadas mediante o jogo político da independência, quando se imponha amalgamá-las numa identidade alternativa a portuguesa e criar as demais condições que garantissem a transição do antigo referencial político --- "a Grande família lusitana” - para um Império constitucional brasílica (COSTA, 2006, p. 415).

Após a separação entre a Metrópole e o Reino, os estadistas luso-brasileiros criaram uma nova "Nação", com a ideia de "Identidade Nacional".

A formulação do projeto que reforçava a "identidade nacional" teve como arcabouço ideológico a ideia da miscigenação do povo brasileiro e a invenção da unidade a partir das diversidades entre as regiões. Neste sentido, a nova nação não mais necessitaria manter o grande território do Brasil unido através da identidade lusitana, mas da identidade nacional brasileira, da miscigenação do índio, negro e português.

\section{CONSIDERAÇÕES FINAIS}

A realidade social é múltipla e os fatos históricos não seguem uma direção única ou linear. Dessa forma, notamos que a formação do Estado Burguês no Brasil se dá em meio a diversos fatores internos e externos que influenciaram aquele momento histórico.

O processo externo da independência deu-se com a Revolução do Porto. Este movimento tinha características liberais para Portugal, mas, pretendia a recolonização do Brasil, objetivo este que fez os estadistas brasileiros repensarem 
suas posturas em relação à ideia de conservar o Brasil como reino unido a Portugal.

Sabe-se que inicialmente os estadistas brasileiros não estavam interessados em romper com Portugal, antes sugeriram que a união dos reinos era a melhor opção para o Brasil. Percebendo que seria impossível este estratagema, uma vez que, a elite mercantil portuguesa queria de volta seu exclusivismo colonial, e temendo a sublevação interna, a direção muda de sentido. Deste modo, a elite política brasileira procura organizar a representação política e a constituinte.

Estrategicamente, as elites, temendo a sublevação popular manipularam um movimento separatista em torno de D. Pedro. Em 1822 forjou-se uma independência de ocorrência pacífica, sem a participação das camadas populares.

Todo esse jogo da elite estadista indica que a emancipação brasileira teve caráter político conservador, uma vez que manteve a Monarquia, a estrutura social e econômica liberal, pois pretendia extinguir o fantasma do retorno à colonização portuguesa retroagindo as conquistas adquiridas a partir de 1808.

Ainda observamos, neste contexto, que os grupos radicais, os quais defendiam a instalação da República, foram absorvidos pelos os moderados ou foram excluídos da vida política logo no começo do Primeiro Reinado.

Por sua vez, a independência não foi uma separação total. 0 Brasil independente continuou sendo uma Monarquia governada por Dom Pedro I, que era filho do rei da nação colonizadora. Situação contrária aos dos outros países da América que após a emancipação tornaram-se Repúblicas.

Dado os fatos anteriores sobre a Independência do Brasil as palavras Revolução e República representavam o mesmo significado na visão da maior parte da aristocracia liberal, pois para essa elite tais palavras refletiam a fragmentação territorial e o comprometimento da sua condição de classe dominante. Por sua vez, a ideia de identidade nacional contribuiu para legitimar a independência do Estado português e forjar a imagem de nação brasileira.

\section{REFERÊNCIAS}

COSTA, Emília Viotti da. Da Monarquia à República: Momentos Decisivos. $2^{\circ}$ ed. São Paulo: Editora Ciências Humanas, 1979. 
FALCON, Francisco José Calazans. A época pombalina. São Paulo: Ática, 1982.

FAORO, Raymundo. Os Donos do Poder. Porto Alegre: globo, 1979.

LINHARES, Maria Ieda. História geral do Brasil. Campinas: Hucitec, 1990

MATOS, Ilmar R. Construtores e herdeiros. A trama dos interesses na construção da unidade política. In: JANCSÓ, Están. (org.). Independência: história e historiografia. São Paulo: Hucitec - FAPESP, 2005, p. 271- 300.

NOVAIS, Fernando A. (org.) História da Vida Privada no Brasil Império: a corte e a modernidade nacional. São Paulo: Companhia das Letras, 1997.

ORTIZ, Renato. Cultura brasileira e identidade nacional. São Paulo: Brasiliense, 2003.

PRADO JÚNIOR, Caio. A formação do Brasil contemporâneo. São Paulo: Brasiliense, 1963.

ROMPATTO. Maurilio. A formação do estado nacional brasileiro. Akrópolis, Umuarama, V. 9, nํ. 4, out./dez., 2001

SILVA, Ana Rosa Cloclet da. Inventando a nação: intelectuais ilustrados e estadistas luso-brasileiros na Crise do Antigo Regime Português (1750-1822). São Paulo: Hucitec: Gapesp, 2006.

SOUZA, Iara Lis Carvalho. Pátria coroada: o brasil como corpo político autônomo - 1780/1831. São Paulo: Ed. Unesp, 1998. 


\section{RESUMO}

0 presente artigo pretende tratar sobre algumas questões que parecem relevantes para compreensão do estabelecimento do Estado Burguês no Brasil. Do contato inicial com o tema nossas reflexões se dirigem para a produção historiográfica a ele concernente. Nos limites deste artigo nos restringiremos às idéias políticas e influências dos estadistas luso-brasileiros para criar o projeto de Nação. Apresentamos as concepções das elites coloniais e a busca de representação de um Estado político ligado aos interesses das elites locais. Discutimos sobre a formação do Império e o rompimento entre a Metrópole e o Reino.

PALAVRAS-CHAVE: Estado brasileiro; política; nação; identidade nacional.

\section{ABSTRACT}

This article intends to deal with on some issues that seem relevant to understanding the establishment of the bourgeois state in Brazil. The initial contact with the theme our reflections are directed to the historiographical production to him presaged. Within the limits of this article in we restrict the political ideas and influences of the statesmen portuguese-brazilian to create the project of nation.

Key Word: Brazilian State, politics, nation, national identity 